\title{
Assessing the costs and benefits of perioperative iron deficiency anemia management with ferric carboxymaltose in Germany
}

This article was published in the following Dove Press journal: Risk Management and Healthcare Policy

\author{
Bernd Froessler ${ }^{1,2}$ \\ Alexandra M Rueger ${ }^{3,4}$ \\ Mark P Connolly ${ }^{5,6}$ \\ 'Department of Anesthesia, Lyell \\ McEwin Hospital, Elizabeth Vale, \\ SA, Australia; ${ }^{2}$ Discipline of Acute \\ Care Medicine, University of \\ Adelaide, Adelaide, SA, Australia; \\ ${ }^{3}$ Vifor Pharma, Munich, Germany; \\ ${ }^{4}$ Charité Universitätsmedizin \\ Berlin, Medizinische Klinik mit \\ Schwerpunkt Kardiologie Campus \\ Virchow-Klinikum, Berlin, Germany; \\ ${ }^{5}$ Unit of PharmacoEpidemiology and \\ PharmacoEconomics, Department of \\ Pharmacy, University of Groningen, \\ Groningen, the Netherlands; ${ }^{6} \mathrm{Global}$ \\ Market Access Solutions Sàrl, St-Prex, \\ Switzerland
}

Background: Perioperative administration of ferric carboxymaltose (FCM) was previously shown to reduce both the need for transfusions and the hospital length of stay in patients with preoperative iron deficiency anemia (IDA). In this study, we estimated the economic consequences of perioperative administration using FCM vs usual care in patients with IDA from the perspective of a German hospital using decision-analytic modeling.

Materials and methods: The model was populated with clinical inputs (transfusion rates, blood units transfused, hospital length of stay) from a previously reported randomized trial comparing FCM vs usual care for managing IDA patients undergoing elective abdominal surgery. We applied a hospital perspective to all costs, excluding surgery-related costs in both treatment arms. One-way sensitivity analyses were undertaken to evaluate key drivers of cost analysis.

Results: The average costs per case treated using FCM compared to usual care were $€ 2,461$ and $€ 3,246$, respectively, for resource expenses paid by hospital per case. This would suggest potential savings achieved with preoperative intravenous iron treatment per patient of $€ 786$ per case. A sensitivity analysis varying the key input parameters indicated the cost analysis is most sensitive to changes in the length of stay and the cost of hospitalization per day.

Conclusion: Perioperative administration of FCM results in cost savings to hospitals based on reduced blood transfusions and length of stay following elective abdominal surgery.

Keywords: intravenous iron, economic evaluation, anemia, iron deficiency, blood transfusion, patient blood management

\section{Introduction}

Preoperative anemia, most commonly attributed to iron deficiency (ID), is present in $\sim 35 \%$ of patients undergoing elective surgery. ${ }^{1}$ ID anemia (IDA) can be caused by multiple factors including insufficient iron absorption and bleeding due to an underlying disease and is associated with a risk of poor outcome for people who undergo surgery. ${ }^{2,3}$ Additionally, blood loss worsens anemia. Red blood cell (RBC) concentrate transfusion is widely used for anemia correction, even though medical and economic considerations argue for restrictive use of this increasingly scarce resource. ${ }^{4} \mathrm{RBC}$ transfusion is associated with both infectious and noninfectious risks. Notwithstanding recent improvements in blood safety, a finite risk of transfusion-transmitted infections remains, along with risks from new pathogens arising that could infect the blood supply. ${ }^{5}$ Noninfectious risks associated with RBC transfusion include (immune-mediated) acute transfusion reactions. ${ }^{6}$ RBC transfusion has shown to significantly increase morbidity and mortality, and to negatively impact overall survival in colorectal cancer patients. ${ }^{7}$
Correspondence: Mark P Connolly Unit of PharmacoEpidemiology and PharmacoEconomics, Department of Pharmacy, University of Groningen, Antonius Deusinglaan I, Groningen 97/3 AV, the Netherlands Email m.connolly@rug.nl 
In addition to the clinical consequences and patient burden, RBC transfusion is costly for health services and society. ${ }^{8}$ Reported costs associated with RBC transfusions to surgical patients in four centers in Europe and the USA ranged between $€ 464$ and $€ 1,053$ per transfused RBC unit. ${ }^{9}$ A Swedish study reported that in addition to the administration costs involved in RBC transfusion, costs associated with transfusion reactions, such as prolonged hospital stay and treatment of viral infections and allergic reactions, accounted for almost $35 \%$ of the total costs. ${ }^{10}$ Furthermore, Leahy et al showed in their retrospective observational study of 605,046 patients, admitted to four major adult tertiary care hospitals, savings of AU\$18,507,092 (US\$18,078,258) and between AU\$80 million and AU\$100 million (US\$78 million and US\$97 million) estimated activity-based savings could be achieved by implementing patient blood management. ${ }^{11}$ Therefore, from both a clinical and economical perspective, minimizing $\mathrm{RBC}$ transfusion has become a desirable goal. ${ }^{12}$

It is recognized that patient blood management interventions, such as pre- or perioperative intravenous (IV) iron administration can be used to minimize the use of blood and blood components during surgery (Joint United Kingdom [UK] Blood Transfusion and Tissue Transplantation Services Professional Advisory Committee). There is evidence that preoperative and peri-partum IV iron offers a well-tolerated approach for clinical and patient-relevant outcome advantages. ${ }^{13-17}$ A recent randomized controlled clinical trial reported that in patients with preoperative IDA, perioperative administration of ferric carboxymaltose (FCM) reduces both the need for transfusions and the hospital length of stay. ${ }^{18}$ However, to inform adoption of FCM into IDA protocols for patients undergoing elective surgery requires economic evidence to justify this added expense for hospitals. The objective of this analysis was to model the economic consequences of perioperative administration of FCM vs usual care in German hospitals (cost comparison model).

\section{Materials and methods}

This research was exempt from ethics approval. Data utilization was based on the results of a clinical trial by Froessler et al. ${ }^{18}$ This trial was approved by the study hospital's human research ethics committee (Ref. No.: 2009108) and registered with the Australian New Zealand Clinical Trials Registry (ACTRN12611000387921). An Excel-based model was developed to investigate the costs of FCM treatment com- pared with usual care in perioperative blood management in elective abdominal surgeries in Germany. The model estimates the average cost per case treated preoperatively with FCM compared with usual care (all anemia treatment modalities as per primary care physician or surgical team) until the point of discharge. No long-term implications are considered. The model considers only the immediate outcomes and associated costs.

The direct hospital cost perspective was applied to the analysis to understand the costs paid by hospitals for each intervention and the likely differences in cost per patient undergoing abdominal surgery. The costs incurred by hospitals and the subsequent diagnostic-related group payment attributed to the surgery performed were not considered in this analysis as they represent revenue for hospitals in relation to procedures provided, and not costs. Discounting was not applied to the budget impact analysis as the hospital budget holder responsible for procurement is interested in real financial streams over time and it is intended as a year-by-year projection to guide budgetary planning and discussions. Microsoft Excel ${ }^{\circledR} 2016$ was used for all the calculations. Based on the treatment allocated, patients transitioned through the model with costs and outcomes accounted at different stages. Entering the model, patients received either FCM or usual care prior to surgery for the management of IDA. Patients in the FCM arm of the model received surgery and postoperative care, including $\mathrm{RBC}$ transfusion for some patients, as seen in the clinical study conducted by Froessler et al. ${ }^{18}$ In addition, patients in the FCM arm received postoperative administration of FCM. In the comparator arm, subjects received usual care prior to their surgery. They continued through the model with surgery and postoperative care, potentially including RBC transfusion. In this randomized controlled trial, a $60 \%$ reduction in RBC transfusion was observed in the IV iron group compared with the usual care group (31.25\% vs $12.5 \%)$. Hemoglobin $(\mathrm{Hb})$ values, although similar at randomization, improved by $0.8 \mathrm{~g} / \mathrm{dL}$ with IV iron compared with $0.1 \mathrm{~g} / \mathrm{dL}$ with usual care $(P=0.01)$ by the day of admission. The IV iron group had higher $\mathrm{Hb} 4$ weeks after discharge compared with the usual care group ( 1.9 vs $0.9 \mathrm{~g} / \mathrm{dL}, P=0.01$ ) and a shorter length of stay ( 7.0 vs 9.7 days, $P=0.026$ ). There was no difference in discharge $\mathrm{Hb}$ levels, morbidity, mortality, or quality of life.

Data inputs in the model are populated with information from peer-reviewed literature, publicly available data sources, and the estimations provided by clinicians. Table 1 provides 
Table I Input parameters for FCM budget impact model

\begin{tabular}{|c|c|c|c|}
\hline Input parameters & FCM & $\begin{array}{l}\text { Usual } \\
\text { care }\end{array}$ & Reference \\
\hline \multicolumn{4}{|l|}{ Treatment-specific data } \\
\hline $\begin{array}{l}\text { Total percentage of patients } \\
\text { transfused in surgery }\end{array}$ & $12.50 \%$ & $31.25 \%$ & $\begin{array}{l}\text { Froessler et al } \\
2016^{17}\end{array}$ \\
\hline $\begin{array}{l}\text { Number of blood units } \\
\text { transfused }\end{array}$ & 1.6 & 3.2 & $\begin{array}{l}\text { Froessler et al } \\
2016^{17}\end{array}$ \\
\hline Length of stay (days) & 6 & 9 & $\begin{array}{l}\text { Froessler et al } \\
2016^{17}\end{array}$ \\
\hline \multicolumn{4}{|l|}{ Cost-specific data } \\
\hline $\begin{array}{l}\text { Cost of an iron therapy } \\
\text { per } \mathrm{mg}\end{array}$ & $€ 0.284$ & $€ 0.284$ & LauerTaxe $2016^{18}$ \\
\hline $\begin{array}{l}\text { Iron }(\mathrm{mg}) \text { needed } \\
\text { preoperatively }\end{array}$ & $\mathrm{I}, 000 \mathrm{mg}$ & $0 \mathrm{mg}$ & $\begin{array}{l}\text { Froessler et al } \\
2016^{17}\end{array}$ \\
\hline $\begin{array}{l}\text { Iron }(\mathrm{mg}) \text { needed } \\
\text { postoperatively }\end{array}$ & $200 \mathrm{mg}$ & $0 \mathrm{mg}$ & $\begin{array}{l}\text { Froessler et al } \\
2016^{17}\end{array}$ \\
\hline $\begin{array}{l}\text { Iron infusion costs } \\
\text { (material+15 minutes } \\
\text { work-related costs) }\end{array}$ & $€ 12.65$ & $€ 0.00$ & $\begin{array}{l}\text { Froessler et al } \\
2016,{ }^{17} \text { Vifor } \\
2016^{21}\end{array}$ \\
\hline Cost of one RBC unit & $€ 97.00$ & $€ 97.00$ & $\begin{array}{l}\text { Hönemann et al } \\
2013^{4}\end{array}$ \\
\hline Hospital day (normal ward) & $€ 350.00$ & $€ 350.00$ & $\begin{array}{l}\text { Dr Thalheimer } \\
\text { (Head of } \\
\text { Controlling), } \\
\text { personal } \\
\text { communication, } \\
2017\end{array}$ \\
\hline
\end{tabular}

Abbreviations: FCM, ferric carboxymaltose; RBC, red blood cell.

an overview of all input parameters with all the references that were used.

\section{Clinical data}

The treatment-related data input is based on the results of the clinical trial by Froessler et al which included 72 patients with IDA prior to abdominal surgery in a university teaching hospital in Adelaide, Australia. ${ }^{18}$ Patients received $15 \mathrm{mg}$ of $\mathrm{FCM} / \mathrm{kg}$ body weight to a maximum dose of $1,000 \mathrm{mg}$ preoperatively and additional IV FCM post-op according to blood loss as per the protocol. The median IV iron dose administered to patients in the intervention group was 1,200 mg (interquartile range 1,088-1,363) for anemia treatment or a standard therapy prescribed by the general practitioner or the surgical team. Clinical metrics used to construct the model were based on reported transfusion rates of $12.5 \%$ in patients receiving FCM compared with $31.5 \%$ of patients receiving standard of care. ${ }^{18}$ We also incorporated the following study findings in our model: FCM patients who in addition to their IV iron treatment received RBC transfusion were administered on average 1.6 units (vs 3.2 units for nonFCM patients) and their hospital length of stay was shorter (6 vs 9 days).

\section{Hospital cost data}

The German hospital cost perspective, excluding labor costs, was applied to this analysis. Cost data were taken from the "LauerTaxe" (price list of the medicinal products sold in Germany; cost of FCM: $€ 141.88 / 500 \mathrm{mg}),{ }^{19}$ the Department of Medical Controlling of Heidelberg University Hospital (estimated cost for 1 day of hospitalization: $€ 350.00$; Dr med. Markus Thalheimer, Head of Medical Controlling, personal communication, 2017), and the St Marienhospital Vechta (cost of blood products: $€ 97.00 / \mathrm{RBC}$ ). ${ }^{4}$ The costs associated with administering FCM and RBC have been excluded from this analysis. The justification for this was to avoid double counting costs, as administration in some cases would have been covered by the daily hospitalization cost applied in the model. A one-way sensitivity analysis was used to determine the impact of all individual model parameters on the results. We derived sensitivity ranges using $\pm 20 \%$ for all parameters except, the price of medications as these are fixed costs to the hospitals. The results shown in Figure 1 indicate how a $20 \%$ positive or $20 \%$ negative change in any one variable will influence the incremental budget impact per case.

\section{Results}

We estimated the average cost per case treated with FCM and usual care to be $€ 2,461$ and $€ 3,246$, respectively, for resource expenses paid by the hospital per case (excluding the surgical expenses). This would suggest potential savings achieved with preoperative IV iron treatment per patient of $€ 786$ per case (Table 2).

In Figure 1, variation around the incremental cost per case with $-€ 786$ shown as the midpoint when varying the sensitive parameters by $\pm 20 \%$ is illustrated using one-way sensitivity analysis. The individual costs per case were most sensitive to changes in hospital length of stay and hospital cost per day, as noted by the wide variation in the incremental budget impact (Figure 1). Additionally, the results were sensitive to the number of milligrams of iron needed preoperatively. The number of units transfused, the cost of RBC per unit, and postoperative dosing had limited impact on the incremental results, as suggested by the limited variation in the incremental budget impact.

\section{Discussion}

The choice of perspective applied in economic assessments of medical technologies and interventions is an important consideration because the analysis focuses specifically on costs and outcomes relevant to a specific sector involved in the delivery of care. In our analysis, we focused specifically on the hospital sector in recognition of the many choices that 


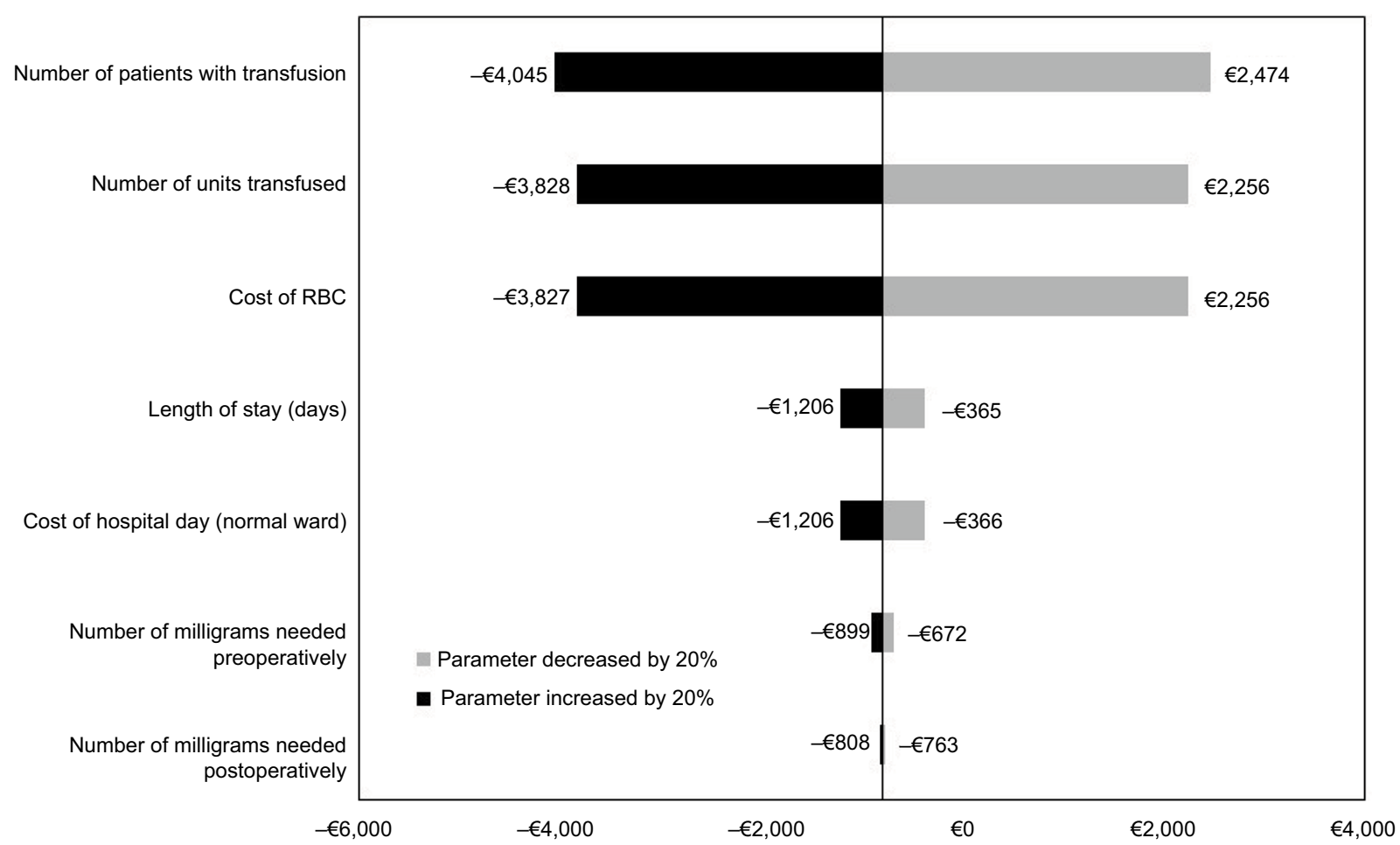

Figure I One-way sensitivity analysis results on the cost difference of FCM vs usual care based on individual case. Abbreviations: FCM, ferric carboxymaltose; RBC, red blood cell.

Table 2 Results of the per patient economic model comparing FCM with usual care

\begin{tabular}{llll}
\hline Outcome & FCM & Usual care & Incremental \\
\hline Cost of an iron therapy & $€ 340.5 \mathrm{I}^{\mathrm{a}}$ & $€ 0.00$ & $€ 34 \mathrm{I}$ \\
Cost of RBC & $€ 20.18$ & $€ 96.22$ & $-€ 76$ \\
Cost of length of stay & $€ 2,100.00$ & $€ 3,150.00$ & $-€ 1,050$ \\
(normal ward) & & & \\
Total & $€ 2,46 \mathrm{I}$ & $€ 3,246$ & $-€ 786$
\end{tabular}

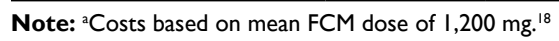

Abbreviations: FCM, ferric carboxymaltose; RBC, red blood cell.

hospitals must make regarding medical technologies. The choice of technologies not only influences outcomes, but also influences potential downstream resources consumed or cost savings. Following health service delivery, hospitals seek reimbursement from insurers for service delivery through diagnostic-related group payment mechanisms. Consequently, when introducing new technologies, hospitals seek to limit expenditure to an amount comparable to the payment they receive or achieve savings within another hospital sector. As described in our analysis, investments in FCM can offer savings attributed to reduction in acquisition of RBC for transfusions and reduced hospitalization duration and, subsequently, operating costs for the hospital. Although costs for pharmaceuticals will increase with FCM, these costs are paid for through reduced spending in other areas, most notable being RBC units and expenses attributed to shorter hospitalization of people with IDA.

Previous studies have explored the cost consequences of FCM in different treatment settings. A French study showed that managing perioperative IDA with FCM resulted in annual cost savings of $€ 216$ per patient undergoing knee and hip surgery. ${ }^{20}$ These outcomes are in line with the cost savings of $€ 786$ per patient described here in a population of IDA patients undergoing abdominal surgery in Germany. Because the underlying goal of FCM treatment is to improve the iron status and outcomes of patients undergoing surgery, it is likely that the results described here would be applicable to other surgical interventions in populations with IDA. This might suggest the economic benefits of adapting FCM more broadly in eligible subjects could have meaningful economic gains for hospitals and patients.

\section{Limitations}

There are several weaknesses to our cost analysis that need to be considered when interpreting our findings. First, the randomized study on which the cost analysis is based was conducted in a single country with an advanced health system, that is, Australia. Therefore, reported outcomes including likelihood for transfusion and hospital duration may vary between countries, which could influence the underlying resources' use on which costs are estimated. Furthermore, 
economic analyses of health care are influenced by the underlying unit costs. Therefore, variation in costs across different geographies could influence the conclusions.

There are several aspects of the modeling approach that may suggest we have undervalued the economic benefits of FCM. First, we have not accounted for the likelihood for productivity gains attributed to improve surgical outcomes in elective procedures. If patients are released from the hospital sooner, this might suggest that patients can return to normal activities sooner. Although small, the improved indirect costs associated with improved productivity would likely improve the societal economic benefits of FCM described here. Second, several labor inputs associated with administration of RBC units and FCM have been excluded. This was done to avoid double counting, as we have already included daily hospitalization costs. However, if RBC was administered outside of the normal hospitalization costs, this would improve the economic outlook of FCM by reducing these costs. Furthermore, in the clinical trial on which the analysis was based, a limited number of individuals in the usual care arm received FCM, which would have increased the costs slightly in the usual care arm, and this was not considered in our analysis.

\section{Conclusion}

Preoperative correction of ID anemia with FCM reduces the need for blood transfusion and the length of hospital stay. Treatment with FCM in IDA resulted in cost savings of $€ 786$ per case in Germany based on reductions in transfusion and costs paid by hospitals for extended hospitalization.

\section{Acknowledgment}

The abstract for this paper was presented at the 8th Annual NATA Symposium on Patient Blood Management, Haemostasis and Thrombosis, April 20-21, 2017, Florence, Italy.

\section{Author contributions}

BF: medical input, study design, interpretation of results, critical revisions of manuscript. AMR: study design, cost inputs, results interpretation, drafting manuscript, and final editing. MPC: study design, model development, clinical data inputs, drafting manuscript, and final editing.

\section{Disclosure}

$\mathrm{BF}$ has received financial support to give lectures, undertake research, attend scientific advisory boards, and undertake consultancies for the New South Wales Department of Health, South Australia Department of Health, Australian Red Cross Blood Service, Australian National Blood Authority, Vifor Pharma Ltd., Switzerland, and CSL Behring Australia. AMR is a paid employee of Vifor Pharma. MPC received research funding from Vifor for his contribution to this work. The authors report no other conflicts of interest in this work.

\section{References}

1. Goodnough LT, Maniatis A, Earnshaw P, et al. Detection, evaluation, and management of preoperative anaemia in the elective orthopaedic surgical patient: NATA guidelines. Br J Anaesth. 2011;106(1):13-22.

2. Musallam KM, Tamim HM, Richards T, et al. Preoperative anaemia and postoperative outcomes in non-cardiac surgery: a retrospective cohort study. Lancet. 2011;378(9800):1396-1407.

3. Hreinsson JP, Jonasson JG, Bjornsson ES. Bleeding-related symptoms in colorectal cancer: a 4-year nationwide population-based study. Aliment Pharmacol Ther: 2013;39(1):77-84.

4. Hönemann C, Bierbaum M, Heidler J, Doll D, Schöffski O. [Kosten der Verabreichung von Blutkonserven im Krankenhaus]. Chirurg. 2013;84(5):426-432. German

5. Ludlam CA, Powderly WG, Bozzette S, et al. Clinical perspectives of emerging pathogens in bleeding disorders. Lancet. 2006;367(9506):252-261.

6. Hendrickson JE, Hillyer CD. Noninfectious serious hazards of transfusion. Anesth Analg. 2009;108(3):759-769.

7. Acheson AG, Brookes MJ, Spahn DR. Effects of allogeneic red blood cell transfusions on clinical outcomes in patients undergoing colorectal cancer surgery. Ann Surg. 2012;256(2):235-244.

8. Kleineruschkamp AG, Zacharowski K, Ettwein C, et al. [Cost analysis of patient blood management]. Anaesthesist. 2016;65(6):438-448. German

9. Shander A, Hofmann A, Ozawa S, Theusinger OM, Gombotz H, Spahn DR. Activity-based costs of blood transfusions in surgical patients at four hospitals. Transfusion. 2010;50(4):753-765.

10. Glenngard AH, Persson U, Soderman C. Costs associated with blood transfusions in Sweden-the societal cost of autologous, allogeneic and perioperative RBC transfusion. Transfus Med. 2005;15(4):295-306.

11. Leahy MF, Hofmann A, Towler S, et al. Improved outcomes and reduced costs associated with a health-system-wide patient blood management program: a retrospective observational study in four major adult tertiarycare hospitals. Transfusion. 2017;57(6):1347-1358.

12. Goodnough LT, Shander A. Blood management. Arch Pathol Lab Med. 2007;131(5):695-701.

13. Leal-Noval SR, Munoz M, Asuero M, et al; Spanish Expert Panel on Alternatives to Allogeneic Blood Transfusion. Spanish Consensus Statement on alternatives to allogeneic blood transfusion: the 2013 update of the "Seville Document". Blood Transfus. 2013;11(4):585-610.

14. Auerbach M, Macdougall IC. Safety of intravenous iron formulations: facts and folklore. Blood transfus. 2014;12(3):296-300.

15. Froessler B, Dekker G, McAuliffe G. To the rescue: the role of intravenous iron in the management of severe anaemia in the peri-partum setting. Blood transfus. 2015;13(1):150-152.

16. Munoz M, Gomez-Ramirez S, Campos A, Ruiz J, Liumbruno GM. Pre-operative anaemia: prevalence, consequences and approaches to management. Blood Transfus. 2015;13(3):370-379.

17. Munoz M, Gomez-Ramirez S, Liumbruno GM, Grazzini G. Intravenous iron and safety: is the end of the debate on the horizon? Blood transfus. 2014; 12(3):287-289.

18. Froessler B, Palm P, Weber I, Hodyl NA, Singh R, Murphy EM. The important role for intravenous iron in perioperative patient blood management in major abdominal surgery. Ann Surg. 2016;264(1):41-46.

19. LauerTaxe. 2016. Available from: https://www.cgm.com/lauer-fischer/ loesungen_lf/lauer_taxe_lf/lauer_taxe_en.de.jsp. Accessed December 10, 2017.

20. Luporsi E, Mahi L, Morre C, Wernli J, de Pouvourville G, Bugat R. Evaluation of cost savings with ferric carboxymaltose in anemia treatment through its impact on erythropoiesis-stimulating agents and blood transfusion: French healthcare payer perspective. J Med Econ. 2011;15(2):225-232. 
Risk Management and Healthcare Policy is an international, peer-reviewed, open access journal focusing on all aspects of public health, policy, and preventative measures to promote good health and improve morbidity and mortality in the population. The journal welcomes submitted papers covering original research, basic science, clinical and epidemiological studies, reviews and evaluations, guidelines, expert opinion and commentary, case reports and extended reports. The manuscript management system is completely online and includes a very quick and fair peerreview system, which is all easy to use. Visit http://www.dovepress.com/ testimonials.php to read real quotes from published authors.

Submit your manuscript here: https://www.dovepress.com/risk-management-and-healthcare-policy-journal 